\title{
The research on Electromagnetic Compatibility of the Autonomous Inspection Robot for Power Transmission Line
}

\author{
Jiayan Liu", Qinyue Tan ${ }^{*}{ }^{1}$, Qianru Zhao ${ }^{1}$, Yu Gu${ }^{1}$ \\ 1 Department of Power and Electrical Engineering, College of Water Resources and Architectural \\ Engineering, Northwest A\&F University, Yang Ling, Shaanxi Province, China 712100 \\ *corresponding author email: qinyuetan@126.com
}

\begin{abstract}
Keywords: power transmission line; autonomous inspection robot; EMC; EMI.
Abstract: At present, the technology of line inspection robot for overhead transmission lines in China and abroad is close to the practical stage. But there are still some problems, such as electromagnetic compatibility (EMC). In this paper, based on the $220 \mathrm{kV}, 500 \mathrm{kV}, 1000 \mathrm{kV}$ and other high voltage transmission lines, the electromagnetic environment of the high voltage and high current for the robot is calculated. The data of the electric field intensity and the magnetic field intensity of the high voltage transmission lines within $0.5 \mathrm{~m}$ are calculated. The situation of electromagnetic interference (EMI) is analyzed. Furthermore, a variety of materials and methods of electromagnetic shielding are compared, and the methods of improving the electromagnetic compatibility of the inspection on robot are proposed, which can provide reference for the EMC design of the inspection robot.
\end{abstract}

\section{Introduction}

Inspection robot research began in the 20th century in the late 1980s; Japan, Canada, the United States and other developed countries have carried out research work for inspection robot. However, there are still some problems exist in the research of autonomous inspection robot, including mechanical structure, power supply, navigation and positioning technology and communications technology [1]. There are stepping motor drive, CMOS camera, control panel, external auxiliary circuits and communications equipment in the inspection robot. Under the environment of longterm work, the robot must be in the strong electromagnetic field. Nowadays, EMI and EMC problem is increasingly serious, and electromagnetic pollution is included in the fourth major public hazards. Therefore, The EMC is also required to take into account of the robot in the design. To eliminate the interference of potential risk in the radio communication and improve the operating system of radio communication, the EMC of the inspection robot is studied in detail in this paper, and the high intensity electromagnetic environment of $220 \mathrm{kV}, 500 \mathrm{kV}, 1000 \mathrm{kV}$ transmission line are calculated, the performance of various shielding materials and shielding methods are compared [2, 3]. Based on the calculation and comparison, the electromagnetic shielding mode of the robot shell is proposed [4]. The function frame of the electric system of the inspection robot is shown as figure1.

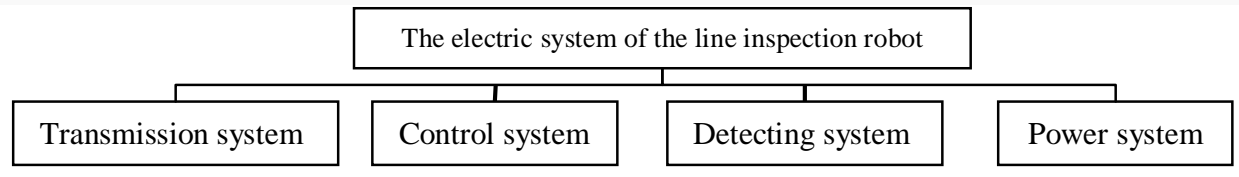

Figure.1 The function frame of the electric system of the inspection robot

\section{The Calculation of Electric Field and Magnetic Field}

Electromagnetic interference around the wire will directly affect the normal operation of the robot, so it is necessary to take into account the electromagnetic environment and the electromagnetic compatibility material of the robot shell [5]. The line inspection robot is suspended on the wire by the mechanical arm, so the working position of the inspection robot is where the distance from the wire $0.1 \mathrm{~m} \sim 0.5 \mathrm{~m}$. In the $220 \mathrm{kV}$ transmission line the electric field intensity calculated with the two 
bundled conductors, in the $500 \mathrm{kV}$ transmission line the electric field intensity calculated with the four bundled conductors, in the $1000 \mathrm{kV}$ transmission line the electric field intensity calculated with the eight bundled conductors. By using the method in reference [6] to solve the field strength generated by each phase wire, and then the three phase vector is superposed, the field strength value can be obtained. The curve of the electric field and magnetic field intensity transformation is drawn, as shown in figure 2 .

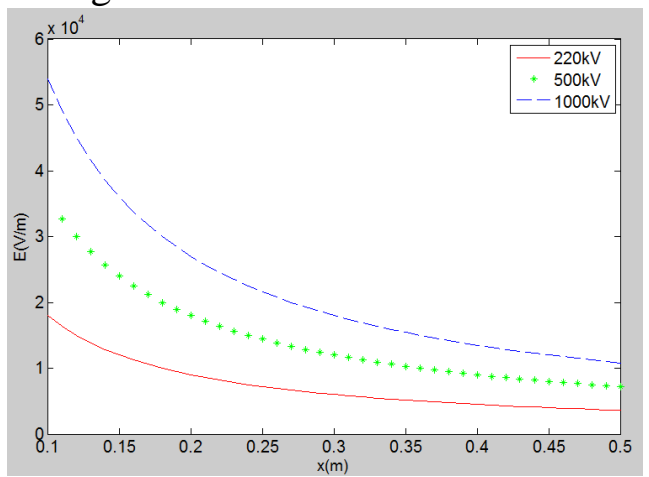

(a)

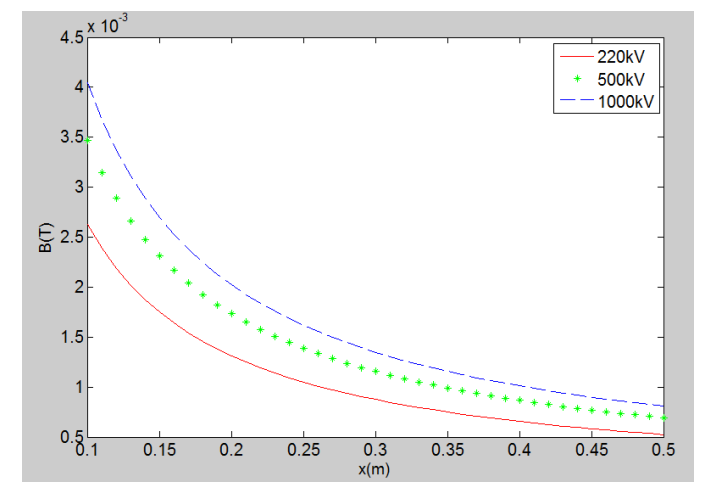

(b)

Figure.2 (a) Relationship between electric field strength and conductor distance (b)Relationship between magnetic field strength and conductor distance

The electric field intensity and the magnetic field intensity distribution curves of $220 \mathrm{kV}, 500 \mathrm{kV}$ and $1000 \mathrm{kV}$ were calculated respectively. The calculate result is shown in table 1 and table 2 .

Table.1 Distribution of electric field intensity

\begin{tabular}{ccc}
\hline \hline $\begin{array}{c}\text { Voltage } \\
\text { level }\end{array}$ & $\begin{array}{c}\text { Maximum } \\
\text { electric field } \\
(\mathrm{kV} / \mathrm{m})\end{array}$ & $\begin{array}{c}\text { Minimum } \\
\text { electric field } \\
(\mathrm{kV} / \mathrm{m})\end{array}$ \\
\hline $220 \mathrm{kV}$ & 19 & 5 \\
$500 \mathrm{kV}$ & 33 & 8 \\
$1000 \mathrm{kV}$ & 53 & 11 \\
\hline \hline
\end{tabular}

Table.2 Distribution of magnetic field intensity

\begin{tabular}{ccc}
\hline \hline $\begin{array}{c}\text { Voltage } \\
\text { level }\end{array}$ & $\begin{array}{c}\text { Maximum } \\
\text { magnetic } \\
\text { field }(\mu \mathrm{T})\end{array}$ & $\begin{array}{c}\text { Minimum } \\
\text { magnetic } \\
\text { field }(\mu \mathrm{T})\end{array}$ \\
\hline $220 \mathrm{kV}$ & 2600 & 500 \\
$500 \mathrm{kV}$ & 3500 & 700 \\
$1000 \mathrm{kV}$ & 4000 & 800 \\
\hline \hline
\end{tabular}

The magnetic field in short circuit around the robot is calculated. Firstly, the maximum current that may occur on the transmission line is calculated, and then the maximum magnetic field can be calculated by the electromagnetic induction formula [7].The line may be short circuit faults, resulting in a greater current, thereby generating a larger magnetic field. After consulting all kinds of documents [8], $220 \mathrm{kV}, 500 \mathrm{kV}, 1000 \mathrm{kV}$ level transmission lines all may be the maximum shortcircuit current is about 50kA. The maximum magnetic field intensity is $2 \times 10^{-2} \mathrm{~T}$, and the minimum magnetic field intensity is $2 \times 10^{-3} \mathrm{~T}$ under the condition of short circuit.

\section{Electromagnetic Compatibility Configuration of Inspection Robot}

The four methods of electromagnetic shielding are presented as follows.

(1) Anti-electromagnetic radiation fiber and mixed fiber fabric. Anti-electromagnetic radiation fiber and mixed fiber fabric are the material with excellent electromagnetic shielding function, which produced by weaving, knitting or nonwoven process, and it is the most flexible and effective processing method. The greater the density of the metal fiber in the fabric and the more the metal fiber is, the better the shielding effectiveness is. But when the distribution density reaches a certain degree, the shielding effectiveness decreased with the increase of the distribution density.

(2) Electromagnetic shielding material brushed on the surface. The surface conductive shielding materials are divided into two kinds of methods: conductive coating and metal cladding. Conductive coating is made of metal powder, carbon black and other conductive filler mixed with a variety of synthetic resin, coated on the surface of plastic. The metal cladding is through the metal spraying, vacuum plating gold method, cathode sputtering, non-electrolytic plating method of polymer insulation materials is obtained on the surface of a thin conductive metal layer, so as to 
achieve the purpose of electromagnetic shielding.

(3) Blend spinning. The inorganic particle or powder with electromagnetic shielding function is blended with the ordinary fiber section for spinning, which is called the blend spinning. It can be made with good conductive fiber, so that the fiber does not lose the original strength, extensibility, washing resistance and wear resistance.

(4) Filled composite shielding composite. The filled composite shielding composite is by the electrical insulation good synthetic resin and has excellent conductive properties of conductive fillers and other additives, the injection molding or extrusion molding and processing all kinds of electromagnetic shielding materials and products. The advantages and disadvantages of different shielding methods are shown as table 3.

Table.3 Comparison of electromagnetic shielding methods

\begin{tabular}{cccc}
\hline \hline Electromagnetic shielding methods & Advantages & Disadvantages \\
\hline $\begin{array}{c}\text { Anti-electromagnetic radiation fiber } \\
\text { and mixed fiber fabric }\end{array}$ & $\begin{array}{c}\text { Light weight, good conductivity, high } \\
\text { strength, not easy broken, wear resistance, } \\
\text { corrosion resistance, good oxidation } \\
\text { resistance, shielding effectiveness }\end{array}$ & $\begin{array}{c}\text { In the development of the industry, the } \\
\text { industry has not been put into use. }\end{array}$ \\
Conductive coating & $\begin{array}{c}\text { Strong applicability, low cost, simple and } \\
\text { practical, and can be mass produced. }\end{array}$ & $\begin{array}{c}\text { Construction environment is } \\
\text { relatively poor, the shielding } \\
\text { effect is limited }\end{array}$ \\
Metal cladding & $\begin{array}{c}\text { Good shielding performance } \\
\text { Blend spinning }\end{array}$ & $\begin{array}{c}\text { The process is complex, subject to } \\
\text { various conditions, the price is } \\
\text { expensive }\end{array}$ & $\begin{array}{c}\text { Shielding performance is not high, high } \\
\text { frequency shielding performance will } \\
\text { decline }\end{array}$ \\
Filled composite shielding & Having excellent electrical conductivity, high & Shielding effectiveness and good \\
composite & comprehensive performance. & Shielding reliability is not very high
\end{tabular}

$\overline{\text { From the above comparison of anti-electromagnetic radiation fiber and matrix fiber fabric method }}$ is still in the domestic research and development stage, no formal investment in industrial production, and therefore will not be used. Metal cladding method is complex, technical requirement and high cost, and the economic benefit of the shield shell of the robot is not good. Filled composite shielding composite method in the additive dispersion problems still need to be improved, so the shielding reliability is not high, inspection robot needs to endure for a long time, long-distance transmission line maintenance, so this way are not suitable. The cost of blend spinning and conductive coating are neither high, and both of the two methods have good Shielding effect. But in contrast, the conductive coating method is more simple and convenient, and it is recommended that the metal shell of the inspection robot is shielded by conductive coating method. Based on the above discussion, conductive coating method is used for electromagnetic shielding, for this need to paint a layer of shielding metal coating on the shell of the robot. The advantages and disadvantages of different shielding materials are shown as table 4.

Table.4 Advantages and disadvantages of different shielding materials

\begin{tabular}{ccc}
\hline \hline Materials & Advantages & Disadvantages \\
\hline Silver & Highest conductivity & Expensive \\
Carbon & Cheap & Lowest conductivity \\
Nickel & Good magnetic and plasticity & Unstable and not environmentally friendly \\
Copper & High conductivity & Easy oxidation \\
\hline \hline
\end{tabular}

Through the comparison of the advantages and disadvantages of different materials, the copper layer is the lowest electromagnetic shielding cost, and easy to operate, suitable for the use of high voltage autonomous inspection robot. But the copper surface prepared will quickly form $\mathrm{Cu}_{2} \mathrm{O}$ and $\mathrm{CuO}$ films, which result in the electrical conductivity of this material decreased rapidly. Therefore, in the use of copper coating, it is necessary to use the anti-oxidation technology, such as additive reducing agent, to improve the stability of electromagnetic shielding. 


\section{Conclusions}

The electric field intensity and magnetic field intensity are calculated. The maximum electric field intensity is $53 \mathrm{kV} / \mathrm{m}$, and the minimum electric field intensity is $5 \mathrm{kV} / \mathrm{m}$. The maximum magnetic field intensity is $4000 \mu \mathrm{T}$, and the minimum magnetic field intensity is $500 \mu \mathrm{T}$. The advantages and disadvantages of various shielding materials and methods are calculated and compared by using this data. It's found that the use of conductive coating with copper coating and adding anti-oxidation technology is the best method of electromagnetic shielding. This method is especially suitable for the electromagnetic shielding requirements of the autonomous inspection robot working on $220 \mathrm{kV}$, $500 \mathrm{kV}$ and $1000 \mathrm{kV}$ voltage level. The method has the advantages of simple operation, strong practicability, low cost, long service life, high shielding reliability and excellent shielding effect, which provides a new method of the research on electromagnetic compatibility of the autonomous inspection robots for power transmission line.

\section{Acknowledgements}

This work was financially supported by the National Natural Science Foundation (51577157), and supported by the Students' Innovation and Entrepreneurship Training Program of Northwest A\&F University.

\section{References}

[1] Zhang Y C, Liang Z Z, Tan M. Mobile Robot for Overhead Power line Inspection-a Review [J]. Robot, 2004, 26(5):467-473. (in Chinese).

[2] Huang C Y, Wu C C. The EMI shielding effectiveness of PC/ABS/nickel-coated-carbon-fiber composites [J]. European Polymer Journal, 2000, 36(12):2729-2737(in Chinese).

[3] Wojkiewicz J L, Hoang N N, Redon N, et al. Intrinsically conducting nanocomposites: high performance electromagnetic shielding materials[C]. IEEE, International Symposium on Electromagnetic Compatibility and Electromagnetic Ecology. IEEE, 2005:58-61.

[4] Nayak S K, Thomas M J. Computation of EMI fields generated due to corona on high voltage over head power transmission lines[C]. Electromagnetic Interference and Compatibility, 2001/02. Proceedings of the International Conference on. IEEE, 2002:15-19.

[5] He J Y. A New Branch of Science and Technology_EMC [J]. Journal of Xi'an Jiao Tong University, 1993, 19 (1):86-90(in Chinese).

[6] Nekhoul B, Feuillet R. A new method for calculating the transient electromagnetic field radiated by a power transmission line[C]. International Conference on Electromagnetic Compatibility. 1994:143-147.

[7] Bo Tang, You Xian Peng, Hong Ying Cao, et al. Electromagnetic scattering field calculation of UHV power transmission line at VHF based on fitting algorithm[C]. IEEE International Conference on Applied Superconductivity and Electromagnetic Devices. IEEE, 2015.

[8] You-Jun Y E, Bao A X, Cheng Y Z. Control of short-circuit current for Zhejiang $500 \mathrm{kV}$ power grids [J]. East China Electric Power, 2006. (in Chinese). 